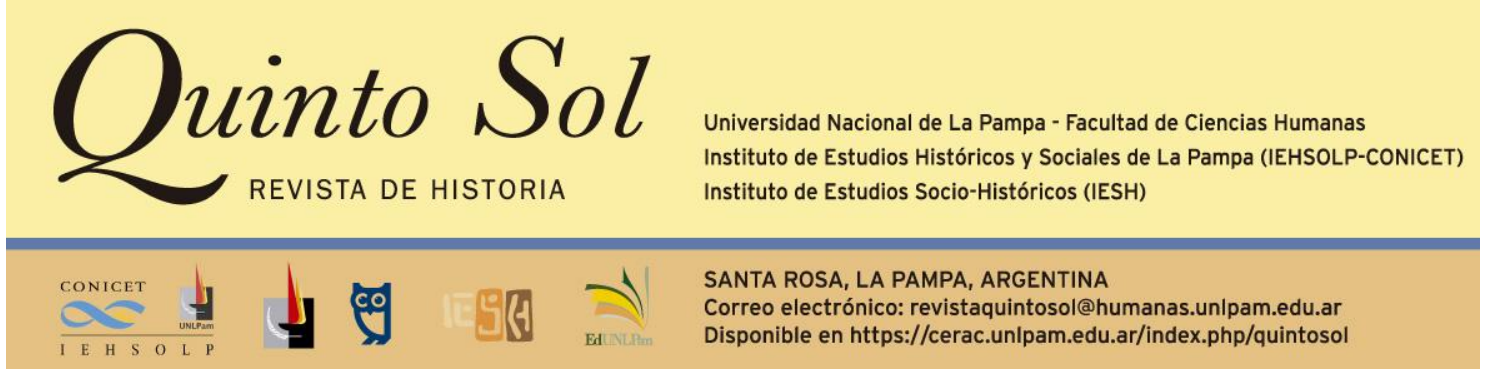

Quinto Sol, vol. 26, n 1, enero-abril 2022, ISSN 1851-2879, pp. 1-19

https://doi.org/10.19137/qs.v26i1.5597

Esta obra se publica bajo licencia Creative Commons 4.0 Internacional. (Atribución-No Comercial-

Compartir Igual)

\title{
Entre el Gran Acuerdo Nacional y Trelew: alcances y significaciones de los conceptos de socialismo nacional y peronismo
}

\author{
Between the Gran Acuerdo Nacional and Trelew: Scopes and \\ meanings of the concepts of national socialism and Peronism
}

\section{O Grande Acordo Nacional e Trelew: alcances e significações dos conceitos de socialismo nacional e peronismo}

\author{
Valeria Caruso \\ Consejo Nacional de Investigaciones Científicas y Técnicas \\ Universidad de Buenos Aires. Instituto de Investigaciones de Estudios de Género \\ Argentina \\ Correo electrónico: caruso.valeria@gmail.com
}

\section{Resumen}

Este trabajo analiza las concepciones sobre el socialismo nacional y el peronismo que distintos referentes de la izquierda peronista expusieron en un ciclo de mesas redondas realizado en septiembre de 1972. Se ensaya un abordaje cercano a la propuesta teórico-metodológica elaborada por Reinhart Koselleck para el estudio de los conceptos políticos que permitirá recuperar la dimensión contingente y cambiante de las ideas políticas que predominaron

Palabras clave izquierda peronista peronismo socialismo nacional 
en los debates de la izquierda peronista a principios de los años setenta, y que posibilita indagar acerca de las conexiones entre peronismo y socialismo que se dieron durante el período.

\section{Abstract}

This paper analyzes the conceptions about national socialism and Peronism that different referents of the Peronist left presented in a round table cycle held in September 1972. An approach close to the theoretical-methodological proposal elaborated by Reinhart Koselleck for the study of political concepts is tested to allow to recover the contingent and changing dimension of the political ideas that predominated in the debates of the Peronist left at the beginning of the 1970s, and that makes it possible to inquire about the connections between Peronism and socialism that occurred during the period.

\section{Resumo}

Este trabalho analisa as conceições sobre socialismo nacional e o peronismo que diferentes referentes da esquerda peronista expuseram em um ciclo de mesas-redondas realizadas em setembro d 1972. Ensaia-se uma abordagem próxima à proposta teórico-metodológica elaborada por Reinhart Koselleck para o estudo dos conceitos políticos que permitirão recuperar a dimensão contingente e variável das ideias políticas que predominaram nos debates da esquerda peronista a princípios dos anos setenta e que aconteceram durante esse período.

\section{Keywords}

Peronist left

national socialism

Peronism

Recepción del original: 05 de febrero de 2021.

Aceptado para publicar: 30 de julio de 2021. 


\section{Entre el Gran Acuerdo Nacional y Trelew: Alcances y significaciones de los conceptos de socialismo nacional y peronismo}

\section{Introducción}

Durante los primeros años de la década del setenta, el concepto "socialismo nacional" fue enunciado por distintos referentes del peronismo como expresión de las proyecciones políticas que motorizaba el movimiento proscripto. Tantos los sectores que se identificaban con la izquierda peronista ${ }^{1}$ como, incluso, aquellos a los que se los podría identificar con posiciones más conciliadoras, enunciaron esa fórmula al momento de situar sus intenciones políticas. Recordemos que el propio Juan Domingo Perón, en 1967, había posibilitado la vinculación del ideario socialista con el de su doctrina, al plantear que el "nacionalismo no tiene por qué estar reñido con el socialismo", dado que "ambos, en el fondo, lejos de ser antagónicos, pueden unirse con un objetivo común de liberación de los pueblos y de los hombres" (Perón, 2017, p. 278).

Esta cuestión ha sido abordada en investigaciones de diverso alcance. Distintos autores han analizado las transformaciones que se produjeron en el ala izquierda del peronismo durante el período de la proscripción (1955-1973) y sus zonas de proximidad con el universo nocional marxista (James, 1976; 1990; Gil, 1989; Bozza, 2001, 2010; Raimundo, 2004). Otros trabajos han centrado la mirada en las formas en que las organizaciones armadas y sus órganos de prensa se expresaron en torno a la noción "socialismo nacional" (Gillespie, 2008; Lanusse, 2010; Bartoletti, 2011; Slipak, 2015; Campos, 2016; González Canosa, 2017; Otero, 2019). En base a estos valiosos aportes, intentamos iniciar un recorrido que nos permita delinear una historia conceptual del pasado reciente por fuera de la búsqueda de índices de "radicalización" o del dilema de la violencia política revolucionaria, para indagar en las modulaciones intelectuales de aquellos y aquellas que desplegaron distintas modalidades de intervención política hacía el interior de la izquierda peronista durante los primeros años de la década del setenta.

En esa búsqueda, el encuentro fortuito con un volumen de 85 páginas, compuesto por las trascripciones de tres mesas redondas que se desarrollaron durante el mes de septiembre de 1972 en distintas sedes sindicales, nos habilitó una vía de acceso para aproximarnos a los pareceres que distintos referentes políticos, sindicales y culturales vinculados a la izquierda peronista sostuvieron respecto de los fines y alcances que la noción de "socialismo nacional" contenía para el peronismo, en un contexto político signado por la inminente apertura electoral auspiciada por el "Gran

\footnotetext{
1 La categoría izquierda peronista puede ser pensada como un clasificador "politético" siguiendo la propuesta de Rodney Needham (1975). Esto permite situar históricamente las distintas reapropiaciones creativas realizadas por diversos actores que nutrieron el universo significante de la izquierda peronista (Caruso, Campos, Vigo y Acha, 2017).
} 
Acuerdo Nacional" (GAN) promovido por el Gobierno de facto de Agustín Lanusse, la potencial participación legal del peronismo en los comicios luego de 18 años de proscripciones (Amézola, 1999) y la cercanía temporal con la masacre de Trelew (Pittaluga, 2006).

Estos encuentros fueron promovidos por los Centros Iberoamericanos para la Liberación Nacional (CIPLEN), una institución coordinada por Carlos Oscar Suárez y Juan José Hernández Arregui. La convocatoria era presentada en estricta obediencia a las exhortaciones de Juan Domingo Perón, con la intención de que estas discusiones funcionaran "como elemento útil para la acción política de los compañeros militantes de base". ${ }^{2}$ Este ciclo se realizó en las sedes de sindicatos identificados con la tendencia combativa, como la Federación Gráfica Bonaerense (FGB), la Asociación de Empleados de Farmacia (ADEF) y la Federación de Obreros y Empleados Telefónicos de la República Argentina (FOETRA). Puede inferirse que la elección de estos ámbitos estuvo determinada por las disputas políticas que los combativos mantuvieron con la tendencia dialoguista liderada por José Ignacio Rucci, quien desde 1970 era el secretario general de la Confederación General del Trabajo de la República Argentina (CGT) y que, en la coyuntura abierta por la dictadura militar a partir del GAN, intentaba posicionarse como el articulador político del sindicalismo peronista (Nahmías, 2013; Dawyd, 2014). En ese contexto, los participantes de estas reuniones consideraban necesario no solo denunciar a Rucci como un exponente de la burocracia sindical dispuesto a neutralizar los reclamos obreros en pos de sus intereses personales, sino también dilucidar los significados que el concepto de socialismo nacional contenía para los trabajadores peronistas.

En ese sentido, entendemos que el análisis de este compendio documental posibilita considerar la agencia intelectual de actores que habitualmente no han sido considerados como tales. Es decir, pensarlos como "productores intelectuales" recuperando a Raymond Williams (1994), en tanto la discusión sobre los significados e implicancias que la noción de "socialismo nacional" contenía para el peronismo implicó explicarse y explicar, narrar y reflexionar en voz alta y junto con otros. Tal como ha planteado Roberto Pittaluga (2016, p. 6), "la tarea de narrarse es también la de poner en el combate político su propia estrategia", a la vez que interviene en la creación de sentidos y significaciones. En este caso, hacer públicos entendimientos que no solo orientaban el accionar político, sino que también, en retrospectiva, iluminan sobre los sedimentos de sentido que condensó esta idea política.

Al respecto, las herramientas de análisis propuestas por Reinhart Koselleck (1993) para explorar el proceso de cambio y consolidación de los conceptos políticos resultan útiles para indagar esta última cuestión. Koselleck ha advertido acerca de los procesos de producción y modificación de las nociones políticas en relación con la paulatina sedimentación de sustratos de experiencia histórica que otorgan significación a los conceptos políticos. Los espacios de experiencia de los hombres y mujeres, en el transcurso de su historia, abren umbrales de expectativa acerca de sus aspiraciones vitales, a la vez que operan en el significado cambiante de las palabras con las que

\footnotetext{
2 Mesas redondas sobre el socialismo nacional (1972). Centros Iberoamericanos para la Liberación Nacional, p. 3. Archivo Carpani, IIPC-TAREA, Universidad Nacional de General San Martín. Ciudad Autónoma de Buenos Aires, Argentina. En adelante, para simplificar la forma de citado en el texto, nos referiremos a estas Mesas redondas como Mesas. Agradezco a Silvia Dolinko e Isabel Plante la posibilidad de acceder a este documento.
} 
nombran el sentido de sus proyecciones y anhelos políticos. De allí que sea importante no perder de vista que un concepto "no sólo indica unidades de acción: también las acuña y las crea. No es solo un indicador, sino también un factor de grupos políticos o sociales" (Koselleck, 1993, p. 206).

Estas claves de lectura pueden contribuir a recuperar la dimensión contingente y cambiante de las ideas políticas que predominaron en los debates de la izquierda peronista a principios de los años setenta. Este trabajo sostiene la hipótesis que los significados que albergó el concepto de "socialismo nacional" pueden ser entendidos como la consolidación de un conjunto de sedimentos de significación que se condensaron a lo largo de los años de proscripción del peronismo, y que otorgaron nuevos sentidos a palabras ya existentes en el vocabulario político vernáculo.

En adelante, la indagación se organiza en tres apartados. En ellos se exploran los contenidos de las argumentaciones vertidas por los expositores en cada uno de estos encuentros y se examinan los ejes mediante los cuales los disertantes vincularon las nociones de peronismo y socialismo nacional. Finalmente, se concluirá el trabajo con una reflexión acerca de cómo esos sustratos de experiencia militante sedimentaron sentidos que habilitaron nuevas concepciones del peronismo a través de la noción de socialismo nacional.

1.

El primer encuentro se desarrolló en la sede de la FGB el 8 de septiembre de 1972. Carlos Suárez, por el Frente Peronista Octubre, inauguró la conversación. Planteaba entonces que el peronismo era "la expresión nacional del socialismo, en la medida que representa, expresa y desarrolla en la acción las aspiraciones de las masas populares y la clase obrera argentina". Para este joven que había iniciado su militancia política en las filas de la Unión Cívica Radical del Pueblo santafecina, y cuyo acercamiento al peronismo se había producido a partir de su vinculación con la CGT de los Argentinos (CGTA) en 1969, el "socialismo que nosotros pretendemos construir... expresa toda la corriente histórica argentina, recoge las tradiciones de lucha de las masas populares en esta etapa de agudizamiento, en que se enfrenta directamente el pueblo con sus dominadores". ${ }^{3}$ En este razonamiento enlazaba las luchas populares pretéritas que encarnaban en el peronismo como expresión de un socialismo autóctono.

Suárez, quien por entonces formaba parte del Consejo Provisorio de la Juventud Peronista, advertía que en esa coyuntura histórica, el "partido militar" y sus secuaces sindicales, "esos cipayos de Rucci, Coria, Taccone", pretendían "desvirtuar realmente lo que es esta bandera revolucionaria peronista que es el Socialismo Nacional". Lo cual obligaba a quienes militaban en el ala izquierda del peronismo a salir a la escena pública para esclarecer las significaciones que buscaban vulnerar sus contrincantes políticos. Suárez citaba textualmente documentos de Perón -como el "Mensaje a la Juventud" de febrero de 1971- que daban cuenta no solo de las falsaciones que realizaban los "burócratas" respecto de "las palabras" del líder. ${ }^{4}$ La palabra textual de Perón funcionaba entonces como resguardo último de la veracidad de las proyecciones sobre el progreso colectivo, solo alcanzable a partir del vector revolucionario que impulsaba la izquierda peronista. Desde su interpretación, la exhortación por el

\footnotetext{
${ }^{3}$ Mesas, p. 5.

${ }^{4}$ Mesas, pp. 6, 8.
} 
socialismo nacional realizada por Perón contenía la promesa de superación definitiva del imperialismo foráneo. De allí que el socialismo nacional fuera concebido como la última frontera para alcanzar la emancipación política y económica en Argentina.

La denuncia de manipulación de los designios de Perón, que Suárez lanzaba contra las burocracias que dirigían la CGT, era retomada por Osvaldo Villaflor. Si bien su intervención era presentada en función de su historial militante como obrero gráfico, no debemos desestimar que Villaflor desde hacía años integraba distintos espacios de militancia vinculados a la izquierda peronista, tales como las Fuerzas Armadas Peronistas, el Peronismo de Base y el sindicalismo combativo. No obstante, subrayaba que comprendía la necesidad de la construcción del socialismo nacional en el país no a partir de la lectura de textos teóricos, sino en función de la rememoración de la pobreza y explotación padecidas. Esas vivencias lo habían llevado a entender que "esa palabra que suena tan rara a veces, como es Socialismo Nacional" perdía su extrañeza y adquiría significación como vehículo para erradicar la opresión del capital. Esa significación, desde la perspectiva de este militante del Peronismo de Base, se encontraba inscripta tanto en los orígenes del peronismo como en las proclamas de Eva Perón en su exhortación a "terminar en este siglo con la raza de los explotadores". ${ }^{5}$ A su juicio, esa era la consigna que expresaba el peronismo con dicha noción.

Por su parte, Luis Tossi planteaba que la sociedad argentina se encontraba en un período de transición en el que el peronismo erosionaba el sistema de dominación existente. Más que una guerra, como había declarado recientemente el presidente de facto Lanusse, en Argentina se estaba produciendo la transformación del sistema político en la que dicha fuerza impulsaba la construcción de un poder popular que instauraría el socialismo en el país. El movimiento proscripto excedía al tipo de organización política resultante del sistema de partidos tradicionales, ya que "se transforma por sus luchas de liberación nacional y social en el guardián de que aquí la cosa se corte por la contradicción fundamental imperialismo-nación y la indisolublemente inscripta en ella: antipueblo-pueblo". 6

Este referente del Ateneo de Estudios Sociales de la localidad bonaerense de San Justo advertía que, si en el momento de emergencia del peronismo, el expresidente no había utilizado el término "socialista" para caracterizar a su movimiento, la omisión respondía a que por ese entonces la noción estaba asociada a propuestas "que pertenecían a una clase de la burguesía europeizante" nucleada en torno al Partido Socialista Argentino (PSA). ${ }^{7}$ Sin embargo, en el devenir de los años de proscripción y en las luchas por la vigencia del peronismo, el pueblo había recuperado el término socialismo para expresar sus anhelos de justicia social.

En ese proceso, la clase trabajadora encarnaba el "eje hegemónico por el que pasa el desarrollo de la lucha y el desarrollo de la construcción del Socialismo Nacional", ya que es "la única que representa y concentra en sí misma los intereses exactamente opuestos a los del sistema oligárquico-burgués-imperialista". Las y los obreros eran quienes brindaban "todo el sacrificio en el desarrollo de nuestra sociedad, en la evolución del hombre y a pesar de eso, y en nuestro sistema, es la menos recompensada, la más injustamente recompensada". Por eso resultaba legítima la proyección de constituir un poder popular para instaurar el socialismo en el país, no

\footnotetext{
${ }^{5}$ Mesas, p. 9.

${ }^{6}$ Mesas, p. 15.

${ }^{7}$ Mesas, pp. 10-11.
} 
mediante la lucha armada, sino por el despliegue de la organización de las bases. Estas debían impulsar la "movilización y organización popular", que desembocaría en "asambleas populares, que deben brotar donde aparezca un conflicto, cualquiera sea, hasta que el pueblo todo se encuentre en estado de asamblea", y así constituir "un poder popular paralelo al régimen oligárquico-burgués-imperialista". ${ }^{8}$ Su propuesta proyectaba la diseminación de organismos de base en todo el país, a partir de la elección de referentes "que surjan del voto universal y democrático, de las asambleas populares, que cumplirán funciones deliberativo-legislativas y resolutivo-ejecutivas". Esa democracia directa que las bases debían construir para el ejercicio de sus derechos soberanos implicaba la realización de los programas obreros de Huerta Grande, La Falda, el Mensaje del $1^{\circ}$ de mayo de la CGTA y del Plenario de Gremios Combativos, en lo referido a la nacionalización y socialización de "la política, la economía, el poder y la cultura" en beneficio de los trabajadores y trabajadoras argentinas. ${ }^{9}$

Por su parte, Mario Aguirre se presentaba como exponente de los hombres del interior e informaba que su reflexión era producto de sus vivencias como dirigente sindical peronista, pero, sobre todo, como trabajador. Ese recorrido militante lo hermanaba con otros trabajadores, en el convencimiento de que "los obreros hemos aprendido a intelectualizarnos un poco y nosotros los negros decimos que nos dividieron para diezmarnos". La "intelectualización" a la que alude Aguirre es una cuestión a la que otros dirigentes sindicales, que participaron de este ciclo de discusiones, también se refirieron al momento de presentar sus pareces políticos. ${ }^{10}$

Para este dirigente de la Asociación Trabajadores del Estado -ATE- de Rosario ya no era posible conformarse con "detenernos en la oferta y la demanda, en la renovación del convenio, en golpear la puerta del general amigo", porque la contracara de ese proceder "se ve claramente cuando 16 patriotas -hace pocas horas- caen en Trelew por las manos de esos mercenarios y el pueblo ni tiene derecho a darles la sepultura que se merecen". ${ }^{11}$ Consideraba que "con acciones parciales no vamos a conseguir el objetivo trascendente de liberación integral, y dentro de este concepto de liberación integral, la construcción del Socialismo Nacional". ${ }^{12}$

El peronismo, en la reflexión política de Aguirre, expresaba los anhelos emancipatorios de la clase obrera argentina. Anhelos que se habían forjado no solo en la lucha por la vigencia del movimiento proscripto, sino también en la concientización de las condiciones de explotación de la que eran objeto y en la posibilidad de su erradicación a partir de la construcción del socialismo nacional. Aunque -aclaraba- su concepción de socialismo era distinta de aquella que en 1945 había sido "usurpada por aquellos 'izquierdistas' que estaban ligados directamente a la oligarquía nativa y, por ende, al imperialismo". Sin embrago, desde 1955, señalaba que el socialismo expresaba

\footnotetext{
${ }^{8}$ Mesas, pp. 11, 14.

9 "El control obrero de los medios de producción, y en definitiva, al final del camino, la autogestión de la clase trabajadora al frente de lo que ya en ese momento no van a ser empresas sino talleres al servicio de las necesidades del pueblo organizado". Mesas, p. 12.

${ }^{10}$ Nos referimos puntualmente a las intervenciones de Leandro Fote y Benito Romano, que se analizarán en el segundo y tercer apartados de este trabajo, respectivamente.

${ }^{11}$ Refiere al fusilamiento de 16 militantes de organizaciones guerrilleras por parte de un grupo de oficiales y suboficiales de la Marina en la base Almirante Zar de la ciudad de Trelew (provincia de Chubut), el 22 de agosto de 1972. Tres días después se realizó el velatorio de los militantes asesinados en el local del Partido Justicialista en la ciudad de Buenos Aires, que terminó siendo impedido por la represión policial.

${ }^{12}$ Mesas, p. 16.
} 
las reivindicaciones del peronismo como vector que "apunta a la felicidad del pueblo y la grandeza de la patria, dentro de un mundo que marcha inexorablemente hacia las democracias populares". ${ }^{13}$

Recapitulemos sobre algunas cuestiones que emergen del análisis de este primer encuentro. Según los expositores aquí reunidos, el peronismo se transformaba en las luchas por su vigencia, en tanto encarnaba los anhelos de emancipación del pueblo oprimido. Esas luchas habían dotado de nuevos sentidos a la palabra socialismo. Esta ya no remitía a los antagonistas del PSA, que durante las décadas del cuarenta y cincuenta se habían apropiado de sus significaciones, sino a las fuerzas populares que se identificaban con la fuerza política proscripta. La noción había sido recuperada y resignificada en los programas obreros elaborados durante la década del sesenta por la clase obrera peronista. Por otro lado, los disertantes subrayaron el sentido de la experiencia de la proscripción, aunque también de las privaciones económicas padecidas como dinamo de las significaciones que el socialismo nacional contenía para ellos. A la vez, resonaba afín tanto a las promesas de eliminación de la explotación lanzadas por Eva Perón como a la conquista de justicia social que postulaba la doctrina peronista. En este marco, estos dos entendimientos -el del peronismo y el del socialismo, que casi dos décadas atrás parecían antinómicos- ahora eran concebidos como convergentes.

2.

La segunda de estas mesas redondas se realizó en la sede porteña del sindicato de Farmacia el 15 de septiembre de 1972. Jorge Di Pascuale, secretario general de $A D E F$, inauguró la segunda sesión de discusión y señaló que incluso los contrincantes políticos y sindicales de la izquierda peronista, "los Rucci, Petrov y quizás Balbín o Lanusse", utilizaban el término "socialismo nacional" para nombrar el engaño con el que arremetían contra el pueblo. Por eso resultaba imprescindible dilucidar el significado profundo que entrañaba esa formulación ante los intentos de los burócratas y enemigos del peronismo por desvirtuar sus fines y alcances. Desde la perspectiva de este antiguo referente del Movimiento Revolucionario Peronista (MRP), ${ }^{14}$ el "socialismo nacional" condensaba el sentido de las luchas que el movimiento proscripto llevaba adelante desde 1955. A partir de su salida del poder del Estado, otras fuerzas políticas se habían acercado al peronismo, incluso aquellas que en el pasado habían sido antagónicas. Advertía entonces que si bien el "peronismo comienza con lo que se llama la humanización del capital", en la actualidad de su doctrina "no aceptamos ninguna posibilidad de luchar por la liberación dentro de lo que puede ser la humanización del capital. Hoy aceptamos la lucha por el pueblo en el poder, con la desaparición del capital y por lo tanto de los explotadores y explotados". ${ }^{15}$

La historia por la vigencia del peronismo había confirmado que, dentro del sistema capitalista, "no hay solución para los trabajadores". Solo fuera de él sería posible "formar lo que hemos llamado el hombre nuevo, ese hombre sano, limpio, puro de ideales". Y "para dar el paso a la construcción de ese hombre, tenemos que romper este sistema y a través de él, ir construyendo lentamente lo que tiene que ser una nueva mentalidad". Para Di Pascuale, el "socialismo nacional" se proyectaba como "la

\footnotetext{
${ }^{13}$ Mesas, p. 18.

${ }^{14}$ Sobre la experiencia del MRP, véase el trabajo de Marcelo Raimundo (2000).

${ }^{15}$ Mesas, p. 33.
} 
superación inmediata a la etapa vivida hasta $1955^{\prime \prime}$ y, por lo tanto, expresaba una nueva concepción que permitiría:

poner la sociedad al servicio del hombre y al hombre al servicio de la sociedad; rescatar entonces los valores morales y éticos, la honradez y la humildad, como eje fundamental de esta etapa; socializar los medios de producción, nacionalizar la banca, realizar una profunda reforma cultural, entregar en administración la tierra al que la trabaja mediante una profunda revolución agraria, nacionalizar el comercio exterior. ${ }^{16}$

El socialismo nacional no era ya una noción foránea, construida desde lo abstracto de los escritorios doctos, sino que guiaba las luchas de los y las peronistas. Las contiendas obreras contra las decisiones gubernamentales que oprimían al pueblo peronista habían actuado en la nacionalización de la noción de socialismo en los siguientes términos: "Cuando decimos Socialismo Nacional decimos su propia socialización, y por ello será nacional, sin moldes prefijados, nada que restrinja el espíritu creador del pueblo, de nuestro pueblo". ${ }^{17}$

En ese marco, este adherente al Peronismo de Base evocaba el legado político de Eva Perón para fundamentar su juicio respecto de que la única manera de finalizar con la lucha de clases existente en el país requería de la erradicación de la explotación capitalista y de sus artífices. Por eso, era preciso no perder de vista que:

los explotadores conforman una raza internacional, y los explotados sabrán solidariamente unirse para dar coherencia a la lucha por la liberación de cada Nación. Cada pueblo hará su revolución, desde su perspectiva y desde su realidad histórico-política y ella estará ligada a todos los pueblos oprimidos de la tierra, porque la concepción básica de una política revolucionaria nos dice que donde existe un explotado, existe un hermano. ${ }^{18}$

Como se puede observar, la intervención de este sindicalista expresaba un cúmulo de expectativas relativas a la mundialización de la revolución proletaria. Pensaba, desde su tiempo histórico, que la transformación del orden de cosas existente parecía estar próxima a realizarse. El accionar de los explotados del mundo, desde su visión, permitiría arremeter contra sus explotadores para conquistar la justicia social que, en el ámbito local, perseguía desde sus inicios el peronismo. Ya no para reinsertarse en la órbita del capitalismo mundial, sino en pos de la fundación de un orden nuevo, imaginable en función de la idiosincrasia del pueblo argentino. ${ }^{19}$

Estas consideraciones entraban en estrecha relación con las que posteriormente realizó Roberto Páez, referente de la Agrupación "Revolución Peronista". Desde su perspectiva, el socialismo nacional no resultaba un entendimiento exótico del

\footnotetext{
${ }^{16}$ Mesas, p. 34.

${ }^{17}$ Mesas, p. 35.

${ }^{18}$ Mesas, p. 37.

19 La "patria socialista la construimos con todos los que asuman el compromiso revolucionario de construirla. Socialismo es uno para todo el mundo: cuando decimos Socialismo Nacional es porque respetamos las formas socialistas de otros países, y además exigimos respeto por las formas socialistas que dará nuestro pueblo o nuestra Argentina". Mesas, p. 37.
} 
movimiento peronista, sino que, por el contrario, era "enarbolado por Perón como consigna estratégica para la nueva etapa del Movimiento Peronista como Movimiento de Liberación Nacional". ${ }^{20}$

No obstante ello, resultaba necesario desvincular la noción de "socialismo nacional" de cualquier derivación proveniente de las "tradiciones políticas del nacionalismo y del socialismo de nuestro país", en tanto el movimiento peronista no era producto "ni [de] un socialismo infantil y desarraigado, ni [de] un nacionalismo oligárquico, ni [de] un nacionalismo artesanal y nostálgico". Sus fines y alcances habían sido reformulados al calor de las luchas que las y los peronistas llevaron adelante a lo largo de su historia, poniendo en evidencia que "fue la alianza del imperialismo y las clases capitalistas la que derribó al gobierno peronista en 1955 y condujo al estado de guerra interno en que se encuentra el país". Ese nudo destituyente y proscriptivo, forjado entre el imperialismo foráneo y sus agentes locales, era el que asfixiaba a la población argentina con la violencia de la explotación capitalista y la represión estatal. Esa alianza opresiva era también la que había actuado en las respuestas y nuevas concepciones que desplegaban los trabajadores y otros actores que acompañaban su causa en torno a la noción de socialismo nacional que se proyectaba desde el peronismo. Lo cual, a su vez, requería aclarar las significaciones que condensaba esta formulación política en un contexto en el que incluso "Rucci, Coria y otros pueden sorprendernos haciendo declaraciones sobre el Socialismo Nacional". Por eso entendía que una de las tareas fundamentales de "la juventud revolucionaria, de las organizaciones revolucionarias, de las organizaciones obreras revolucionarias" era la de establecer la centralidad de los postulados que sostenía la izquierda peronista cuando clamaba por la realización del socialismo nacional en el país. ${ }^{21}$

A continuación, Roberto Digón, secretario general del Sindicato Único de Empleados del Tabaco de la República Argentina (SUETRA), planteaba que, más allá de las diferencias entre los disertantes allí reunidos, todos coincidían en "que el fin de todo esto, sea la terminación de la explotación del hombre por el hombre". Consideraba que el capitalismo, iniciado en los albores de la Revolución francesa, se encontraba en crisis desde las guerras mundiales; una crisis que se había profundizado con el inicio de la segunda posguerra. A partir de entonces, los reclamos de autodeterminación de los pueblos sometidos por las potencias imperiales pusieron en cuestión los derechos de soberanía que estas se arrogaban. Era en relación con ese proceso más amplio que debía entenderse la "revolución popular" del 17 de octubre de 1945. En la interpretación de este dirigente sindical, el surgimiento del peronismo se vinculaba no solo con la irrupción de las masas que reclamaba derechos de soberanía que serían ejercidos por intermediación de sus representantes (es decir, Perón), sino que, además, era el síntoma de un problema más profundo, de escala mundial, que indicaba las limitaciones del capitalismo para sostener su estructura de dominación.

En esa línea, este dirigente del SUETRA señalaba que la emancipación popular que perseguía el peronismo se había dado en dos etapas. La primera de ellas resultaba de las conquistas económicas y sociales alcanzadas entre 1945-1955. No obstante, la abrupta finalización de la primera experiencia peronista puso en evidencia que "no estaban las condiciones dadas en nuestro país para llegar a cumplir la revolución" que modificara por completo el orden de cosas existente, dado que por entonces "no se

\footnotetext{
${ }^{20}$ Mesas, p. 35.

${ }^{21}$ Mesas, pp. 36-38.
} 
tenían [a] los hombres preparados para poder materializar eso, y los que decían que interpretaban el socialismo estaban en la vereda de enfrente". ${ }^{22}$ Consideraba que, en esa coyuntura, quienes sostenían las banderas del socialismo eran contrincantes de la causa del pueblo, y quienes integraban el movimiento peronista no comprendían aún que debían romper con el capitalismo para alcanzar la verdadera emancipación nacional.

La resignificación de las consignas socialistas, siguiendo a Digón, se había dado en esa segunda etapa iniciada en 1955 con la proscripción del peronismo. El cambio de concepciones hacia el interior del movimiento -en el primer momento de esta etapase produjo al calor de las luchas de la resistencia peronista, en su enfrentamiento con los gobiernos antipopulares que pugnaban por su erradicación. Asimismo, advertía un segundo momento, iniciado en junio de 1966, signado por el rechazo a la penetración del capital monopólico en el país, posibilitada por los gobiernos dictatoriales de la autoproclamada "Revolución Argentina". Fue a partir de esa acumulación de experiencias que "comienza a hablarse de Socialismo Nacional" entre los militantes peronistas, y también a "cuestionarnos la propiedad privada" tal como existe en el orden capitalista en los siguientes términos:

queremos la propiedad en función social; porque queremos la nacionalización y estatización de la banca privada y de todo el complejo financiero; porque queremos la socialización de la medicina; queremos la socialización de la cultura, es decir, queremos una revolución cultural. ${ }^{23}$

Esos anhelos se habían condensado en el transcurso de la lucha por la vigencia del peronismo. Luego de años de proscripciones, trabajadores y trabajadoras peronistas arribaban a un nuevo entendimiento acerca del socialismo nacional, "porque está hecho con harina nuestra y con nuestras propias manos, es amasado por nosotros".

En ese sentido, Jorge Cerletti recuperaba "las ideas y los programas" forjados por el movimiento obrero peronista en "La Falda, Huerta Grande, el documento del $1^{\circ}$ de mayo de la CGT de los Argentinos, el plenario de los gremios combativos" como "muestras del pensamiento revolucionario en construcción, en desarrollo". Consideraba que, en esa etapa de expansión del capitalismo monopólico, la noción "Socialismo Nacional":

sintetiza y supera las tres banderas del Movimiento: la Independencia Económica, la Soberanía Política y la Justicia Social. Y decimos que las sintetiza y las supera porque en la etapa de los monopolios no podrá haber Independencia económica sin Socialismo; no podrá haber Soberanía política sin Socialismo y jamás se podrá hablar de Justicia Social sin Socialismo. ${ }^{24}$

De manera implícita, los argumentos de Cerletti entraban en estrecha relación con los que Digón. La incidencia del capital monopólico internacional en el país, posibilitada por gobiernos serviles a los designios del imperialismo, obligaba a asumir que el socialismo nacional que se proyectaba desde el peronismo era el único camino

\footnotetext{
${ }^{22}$ Mesas, p. 39.

${ }^{23}$ Mesas, p. 41.

${ }^{24}$ Mesas, p. 42.
} 
para lograr la emancipación social soberana. La lucha por la consecución de ese socialismo en clave local era concebida en perspectiva con:

\begin{abstract}
la historia de las auténticas revoluciones socialistas contemporáneas [que] ha partido y asumido lo mejor de sus tradiciones nacionales. $Y$ nosotros en la Argentina tenemos una rica historia de luchas populares que podemos ejemplificar a través de los grandes caudillos: Artigas, Facundo Quiroga, el Chacho Peñaloza, Felipe Varela, Irigoyen y Perón. ${ }^{25}$
\end{abstract}

Para este militante, la historicidad de las gestas populares pretéritas habilitaba un puente para el triunfo del socialismo. La conexión entre pasado y presente otorgaba un sustrato de legitimidad para las proyecciones realizadas en torno a la idea de socialismo, en tanto esta no remitía exclusivamente a "la eliminación de la explotación" capitalista, sino también al problema del ejercicio del poder por parte de quienes históricamente habían sido explotados. Desde esta mirada, "el Estado no está por encima de las clases, sino que el Estado es el principal instrumento de dominación de las clases explotadoras". Por eso afirmaba "no hay posibilidad de socialismo ni hay posibilidades de liberación si no se destruye el Estado proimperialista y burgués". La propuesta superadora residía en generar las condiciones para edificar un Estado socialista "de las clases trabajadoras y de las masas explotadas del pueblo argentino". ${ }^{26}$

Leandro Fote celebraba la iniciativa de discutir el socialismo con la clase trabajadora, pero advertiría a los asistentes que "si esta reunión terminara solamente en decir qué es el socialismo -aunque lo explicaran a las mil maravillas- no serviría de nada". Más en un contexto político en el que:

compañeros entregados como Rucci o los Coria, que ven ahora una perspectiva política con los partidos burgueses, que no ven la hora que se largue la carrera para tener un cargo más y seguir macaneándolo al pueblo, seguir macaneando a los trabajadores. ${ }^{27}$

Por eso proponía, antes que discutir en qué consistía el socialismo nacional, analizar las limitaciones existentes para su consecución.

A juicio de este dirigente tucumano de la Federación Obrera de los Trabajadores de la Industria del Azúcar (FOTIA), la primera de ellas residía en el accionar de las burocracias que, en pos de la obtención de beneficios políticos y personales, frenaban la combatividad del movimiento obrero organizado. No obstante, destacaba que "aún quedan dirigentes honestos y todavía quedan compañeros que pueden conducir a la clase trabajadora a la liberación total que necesita".

Este señalamiento venía a cuento de revalorizar la importancia de las conducciones obreras y de sus bases ante cierto paternalismo que advertía en distintos referentes de la izquierda local:

muchos compañeros que hablan de socialismo y que levantan las banderas de su pequeño partidito, dicen: "yo tengo la verdad." Pero a veces no nos damos cuenta de que somos un grupito de compañeros y gritamos: "yo tengo la verdad". Yo he

\footnotetext{
${ }^{25}$ Mesas, p. 43.

${ }^{26}$ Mesas, pp. 44, 45.

${ }^{27}$ Mesas, p. 46.
} 
vivido esta experiencia, porque he visto a muchos compañeros pasar por Tucumán, compañeros de distintas ideologías políticas, tratando de enseñarle a los trabajadores cómo tienen que pelear. Pienso que los compañeros que levantan su plataforma política deberían concurrir a la clase trabajadora y aprender lo que se hace en la clase trabajadora, para recién decir: "Esto es lo que tenemos que hacer". ${ }^{28}$

Fote sostenía que las pretensiones de "verdad" y la arrogancia de distintas "vanguardias iluminadas" a la hora de interactuar con la clase obrera funcionaban como una segunda limitación para la gesta emancipatoria que se pretendía construir. Por eso ensayaba un llamamiento a:

los compañeros que, con distinta ideología, que se creen dueños de la revolución, que nos tenemos que poner de acuerdo. Aquí hay un solo enemigo: que es el capital, que es el imperialismo, el gobierno actual. ... Nadie es dueño de la revolución. Pienso que el pueblo todo, ese es el único soberano de la revolución. Y me atrevo a decir, compañeros, que ni el propio Perón es dueño de la revolución. Por eso pienso que el único heredero y responsable de llevar este proceso revolucionario es el pueblo. Nosotros tenemos la obligación de conducir si es que tenemos la capacidad de conducir; tenemos la obligación de aportar lo que nosotros podemos aportar en beneficio de la revolución. ${ }^{29}$

La senda revolucionaria señalaba que, para su triunfo, era preciso aunar esfuerzos contra los verdaderos enemigos del pueblo: el capitalismo, el imperialismo y sus artífices. También que nadie era "dueño de la revolución", sino que esta era una gesta colectiva en la que la clase obrera tenía un lugar nodal. En esta empresa, los trabajadores eran los artífices de un camino de transformación que determinados actores se creían con potestades para dirigir. Allí residía la tercera limitación para el triunfo del socialismo: no comprender la potencia transformadora del pueblo obrero, no solo para darse sus propias direcciones, sino también para comprender y emprender el proceso hacia el socialismo.

En base a su experiencia como delegado gremial del Ingenio San José, proponía extender este ciclo de mesas redondas "a todos los rincones de la República Argentina", para así conocer e incluir las proyecciones políticas de los trabajadores de todo el país. Lo cual, además, evitaría que políticos e intelectuales, externos al mundo del trabajo, discutieran en solitario perspectivas políticas en las que se les asignaba a un rol pasivo y marginal en la toma de decisiones.

Antes de concluir con este apartado volvamos sobre algunas ideas desplegadas por los disertantes en este segundo encuentro. Se advierte la intención de esclarecer los sentidos que contenía la noción de socialismo nacional para la militancia peronista en un contexto de disputa política con quienes, a juicios de los expositores, intentaban vulnerar las significaciones profundas que albergaba el término para la fuerza política proscrita. La profundidad de esas significaciones es la que se pone en palabras en cada una de las intervenciones analizadas. Portan la densidad histórica de un entendimiento forjado en la experiencia de la explotación y de la opresión política que difícilmente pueda captarse desde las elucubraciones teóricas. En ese sentido, la idea de socialismo nacional que postula este sector del peronismo alberga una promesa de superación no

\footnotetext{
${ }^{28}$ Mesas, p. 47.

${ }^{29}$ Mesas, p. 47. Las cursivas en la cita son nuestras.
} 
solo de las limitaciones coyunturales, sino una transformación estructural, dejada a mitad de camino por la primera experiencia peronista en el poder del Estado. Se imaginan formas alternativas de organización, pero también del ejercicio del poder emergente de la voluntad de las bases en tanto forjadoras de la identidad y de la potencia de la fuerza política proscrita.

\section{3.}

La tercera y última mesa redonda se realizó en la sede capital de FOETRA el 22 de septiembre de 1972. Ricardo Carpani inició la conversación expresando que el "Socialismo Nacional, enarbolado por los sectores revolucionarios del peronismo, es el resultado natural y lógico del proceso histórico de nuestro país y de las luchas de los últimos tiempos". Como puede observarse, reitera un entendimiento que ha estado presente en las exposiciones anteriores respecto de que "la conciencia de la necesidad del socialismo" en el peronismo surgió "naturalmente del nacionalismo revolucionario de nuestras masas a través de toda nuestra historia". ${ }^{30}$

Para Carpani, un hombre que había iniciado su militancia política en las filas de la izquierda nacional, la conjunción entre peronismo y socialismo no resultaba antinómica, sino que, por el contrario, devenía del despliegue de las luchas populares por la defensa de lo nacional. En ese devenir, los y las peronistas habían ampliado las significaciones de los mojones doctrinarios del peronismo al reconocer en la opresión capitalista el determinante de última instancia que limitaba e impedía la plena emancipación de la sociedad argentina. Esa amplificación de sentidos y significaciones de las tres máximas peronistas de "Justicia social, independencia económica y soberanía política" redireccionaban el sentido de una contienda contra la dominación del capital. En esta lectura del proceso en curso, la revolución nacional debía ser realizada por los trabajadores, en tanto encarnación de la historia del pueblo argentino en pos de su liberación y responsables de la reformulación de las consignas clásicas del peronismo.

A continuación, el abogado Luis Cerruti Costa planteaba que resultaba sustancial discutir y esclarecer las implicancias que portaba esa noción como "continuidad histórica del Peronismo", ${ }^{31}$ en tanto podía homologarse con los principios históricos del peronismo referidos a la justicia social, la independencia económica y la soberanía política. El socialismo nacional nada tenía que ver con la integración al sistema capitalista que proponía Rucci, sino que, por el contrario, buscaba su abolición en beneficio de los trabajadores argentinos. ${ }^{32}$

En ese sentido, Tomás Saravi consideraba que el socialismo nacional "es un camino que el movimiento popular está construyendo trabajosamente desde 1945". Si bien entendía que "no está consolidada todavía la organización revolucionaria", subrayaba que el peronismo era "el centro de convergencia de los demás sectores que también están demostrando en la lucha su carácter revolucionario, se prepara para la toma del poder, con el General Perón a la cabeza". ${ }^{33}$

Por su parte, Julio Guillán comenzaba su intervención celebrando la iniciativa impulsada por el CIPLEN, ya que consideraba que estas discusiones contribuirían a la

\footnotetext{
${ }^{30}$ Mesas, p. 62.

${ }^{31}$ Mesas, p. 67.

32 Mesas, p. 65.

${ }^{33}$ Mesas, pp. 68, 70.
} 
formación política e ideológica de los trabajadores que no tenían posibilidades de asistir a la universidad para nutrirse de conocimientos o formarse políticamente. De hecho, apelaba a su experiencia personal para señalar que su formación política era el resultado de su militancia en el gremio de FOETRA, en los siguientes términos:

De mi práctica, con mi relación como un hombre de abajo con los de abajo, surge que nuestra experiencia democrática, en nuestros sindicatos, es una gran demostración de lo que será capaz de hacer la clase obrera cuando tenga la posibilidad de ejercitar esta democracia, que posibilite ampliar los conocimientos y desarrollar más profundamente su sentimiento de clase social explotada. ${ }^{34}$

Desde la óptica de este dirigente telefónico, el ámbito sindical funcionaba como una escuela política que demandaba el ejercicio cotidiano de una democracia de base. El sindicato era el espacio en el que los trabajadores argentinos tomaban conciencia de la explotación de la que eran objeto y en el que elaboraban alternativas para su superación. Consideraba que "las revoluciones no se hacen porque alguien teorizó cómo debía ser la revolución sino porque el hombre busca permanentemente respuesta a todo su desarrollo pleno, a todas sus necesidades, a todas sus ansiedades." ${ }^{\prime \prime 5}$

En esa línea, Alfredo Carballeda iniciaba su intervención señalando que la noción de socialismo nacional que perseguía el peronismo era un concepto abierto. Su significación dependía de "las experiencias y del diálogo con el pueblo, especialmente con su clase trabajadora", de las cuales surgirían "las formas, los mecanismos con los que necesariamente tendremos que dotar a esta sociedad nueva, a la sociedad socialista". Para este dirigente de la agrupación "Lealtad y Soberanía del Peronismo Revolucionario", la idea de socialismo no remitía exclusivamente a la eliminación de la explotación capitalista o a la abolición de la propiedad privada, sino que también implicaba "cuestionar nuestra propia vida, nuestra forma de ser, nuestra formación y nuestra proyección; cuestionar lo que somos aquí y ahora y lo que podemos pensar ser en el futuro". Y ese "futuro histórico" producto "de las experiencias mismas de nuestro pueblo, será la síntesis del Peronismo y el marxismo". ${ }^{36}$

En esa dirección apuntaba Benito Romano al considerar que la trasformación del orden existente sucedería cuando "a lo largo y ancho de nuestro país surjan miles de revolucionarios, que con las armas en la mano o con distintos tipos de acción, sean capaces de ir haciendo retroceder al régimen hasta liquidar este sistema capitalista que ya no tiene razón de ser en nuestro país". ${ }^{37}$ Apelaba a la puesta en marcha de distintas modalidades de lucha para superar los obstáculos que impedían el definitivo establecimiento del socialismo en Argentina.

Para este referente de la FOTIA, uno de esos obstáculos correspondía al accionar burocrático de las cúpulas sindicales que traicionaban las reivindicaciones del movimiento obrero peronista expresadas en los decálogos de Huerta Grande, La Falda y el Mensaje del $1^{\circ}$ de mayo de la CGTA. No obstante, entendía que en tanto "el pueblo

\footnotetext{
${ }^{34}$ Mesas, p. 70.

${ }^{35}$ Mesas, p. 70.

${ }^{36}$ Mesas, pp. 72, 73.

${ }^{37}$ Mesas, p. 74. Las cursivas en la cita son nuestras.
} 
vaya viendo su propia experiencia, de haber organizado desde abajo, vaya haciendo su propia discusión política, se vaya enriqueciendo en la teoría y vaya profundizando la acción", lograría imponer sus intereses por sobre las burocracias. Según Romano, el pueblo argentino "está dispuesto a implementar el socialismo en nuestro país, para que esta patria sea una patria sin explotados ni explotadores. Y para ello tenemos que tomar el poder". Desde su mirada, la comprensión del socialismo estaba dada por "nuestra experiencia en las luchas populares de nuestro pueblo", dejando de lado el énfasis en las enseñanzas forjadas por abstractos anclajes teóricos, en pos de un entendimiento vivencial de sus significaciones. Eva Perón era la referencia a la que apelaba para fundamentar ese conocimiento forjado en la experiencia. Decía:

Eva Perón no tenía conocimientos; posiblemente no había estudiado los textos del socialismo ni nada; pero ha sido una mujer que ha visualizado con la claridad que dá la lucha del pueblo y ha sido su bandera; ha sido un líder de esa clase que ha venido siendo sometida por siglos y siglos en nuestro país. ${ }^{38}$

La capacidad de Evita para interpretar los anhelos y reivindicaciones de los hombres y mujeres oprimidos por el sistema capitalista le había conferido un entendimiento práctico y profundo sobre las significaciones del concepto "socialismo nacional". Apelaba, con este ejemplo, a abandonar las abstracciones de los textos para toparse con la materialidad concreta de los problemas obreros en vez de enarbolar en su nombre banderas que les eran ajenas.

Antes de concluir, retomemos algunos de los argumentos nodales esgrimidos en este último encuentro. Como en las reuniones anteriores, la intención primigenia radicó en explicitar los contenidos que la noción socialismo nacional contenía para la izquierda peronista en la medida que esa palabra también era utilizada por sus contrincantes políticos y sindicales para enunciar sus proyecciones políticas. En ese marco, la necesidad de explicar a qué sentidos se aludía con esa noción obligó a los expositores a desplegar su potencia argumentativa para definir una idea que perdía su extrañeza al situarla en el cauce de las luchas por la vigencia del peronismo. De allí que las y los trabajadores fueran concebidos como el sujeto de esa transformación revolucionaria que prometía realizar el peronismo, en tanto encarnación de la historia del pueblo argentino en pos de su liberación. El sentido y el carácter de su gesta no provenían de un constructo teórico abstracto, sino que emergían de su experiencia práctica en sus combates contra la dependencia extranjera y la explotación capitalista.

\section{Comentarios finales}

Hasta aquí hemos examinado las posiciones de distintas personalidades, de extracciones tanto profesionales como territoriales disímiles, respecto de los contenidos, fines y alcances que la noción de socialismo nacional contenía para el peronismo. En estas intervenciones pudo observarse cómo cada uno de los expositores desplegó diversas síntesis interpretativas que condensaban nuevas conexiones entre dos postulados políticos que dos décadas atrás parecían no solo irreconciliables sino también antagónicas. Los esfuerzos de los disertantes por explicar la amalgama

\footnotetext{
${ }^{38}$ Mesas, p. 74.
} 
contenida en la noción de "socialismo nacional" pueden considerarse como la sedimentación de distintos niveles de significación de la experiencia histórica.

Uno de esos niveles estaba dado por las disputas que mantenían con los denominados "burócratas" sindicales y políticos del peronismo, en tanto estos intentaban transgredir no solo la causa de los trabajadores, sino también las proyecciones que desplegaba la noción de socialismo nacional como égida de liberación.

En un segundo nivel, y en relación con el anterior, consideraban que los trabajadores argentinos, en sus luchas por la vigencia del movimiento proscripto, habían afirmado su convencimiento respecto de que, sin la erradicación de las normativas jurídicas e institucionales sobre las cuales el capitalismo sustentaba su reproducción, no podría lograrse la definitiva emancipación nacional que anhelaban.

En torno a esas comprensiones se desplegaba un tercer nivel, referido al convencimiento acerca de que el peronismo no era un partido político burgués, sino un movimiento de liberación nacional que condensaba las gestas pretéritas y futuras de la emancipación argentina. Las banderas de justicia social y soberanía nacional que desde sus inicios enarbolaba se erigirían ahora en la causa por la erradicación de la explotación capitalista y la opresión política burguesa. Esa meta, una vez más, devenía de la propia experiencia de los obreros argentinos como explotados por el régimen capitalista y oprimidos por el sistema político existente.

En un cuarto nivel, condensaba el convencimiento acerca de que, sin erradicar el capitalismo, sería imposible la definitiva instalación de un poder obrero en el país. El peronismo, en tanto representación de los anhelos de liberación de los y las trabajadoras argentinas, encontraba ahora en el marxismo herramientas para imaginar otro orden de cosas en el que la soberanía del pueblo fuera expresión acabada de su propia historia.

En la reflexión de los distintos representantes sindicales que participaron de estas mesas redondas, la convergencia entre peronismo y marxismo resultaba de un conocimiento práctico alcanzado en sus luchas contra la opresión política y económica experimentada en su devenir como trabajadores. También, en esas intervenciones se advierte la intención de resaltar la capacidad crítica e intelectual de los trabajadores para evaluar su situación -en términos de clase- así como para desplegar, elaborar y comunicar sus elecciones políticas.

La cuestión acerca de cómo construir ese socialismo nacional desde el peronismo fue otra de las ideas que sobrevolaron cada uno de estos encuentros. Para algunos de los disertantes, la clave estaba en la conformación de organismos de base de los cuales emergería el sustento de un poder popular. Para otros, la guerra revolucionaria era la opción que terminaría por imponer la constitución de un Estado socialista en el país. Sin embargo, no había coincidencia acerca del lugar que la lucha armada debía ocupar en la gesta revolucionaria. Para algunos, era necesario dar batalla en los diversos frentes de lucha, lo cual no implicaba, necesariamente, que la adopción de las armas inhibiera otras modalidades de acción.

Para la construcción de una sociedad nueva, con el peronismo no alcanzaba. Esta conclusión emergía al evaluar las causas que habían puesto fin al segundo gobierno de Perón y a los 17 años de lucha por su vigencia en la arena política. Durante esos años, la arbitrariedad de la explotación capitalista y la violencia de las fuerzas del orden contra las masas trabajadoras dejaron como saldo la necesidad de transformar el 
sistema vigente en una coyuntura en la que esa transformación parecía realizable, tal como mostraban los ejemplos socialistas de Cuba y de Chile. Ambas experiencias, junto con la recuperación de la prédica de Eva Perón en clave socialista, fueron presentadas como alegatos de "verdad" por los disertantes que participaron de estos encuentros.

Finalmente, estas intervenciones nos permiten aproximarnos a un conjunto de entendimientos respecto de cómo los actores involucrados pensaron las alternativas políticas de su tiempo. También, explorar las reconfiguraciones de las redes semánticas que contenía la noción de socialismo nacional para estos referentes de la izquierda peronista. Sentidos que abrían el umbral de expectativas del peronismo como horizonte del socialismo nacional.

\section{Referencias bibliográficas}

1. Amézola, G. de (1999). El caso del realismo insuficiente. Lanusse, La Hora del Pueblo y el Gran Acuerdo Nacional. En A. Pucciarelli (Ed.) La Primacía de la Política. Lanusse, Perón y la Nueva Izquierda en tiempos del GAN (pp. 57-116). Editorial Universitaria de Buenos Aires.

2. Bartoletti, J. (2011). Montoneros: de la movilización a la organización. Laborde Editor.

3. Baschetti, R. (1995). Documentos 1970-1973. Volumen I: De La Guerrilla Peronista al gobierno popular. De la Campana.

4. Bozza, J. (2001). El peronismo revolucionario. Itinerario y vertientes de la radicalización, 1959-1969. Sociohistórica, 9-10, 135-169. https://www.sociohistorica.fahce.unlp.edu.ar/article/view/SHn9-10a05

5. Bozza, J. (2010). Una voz contra los monopolios CGT. El periódico de la CGT de los Argentinos. Oficios Terrestres, 25 (15), 83-94. http://sedici.unlp.edu.ar/handle/10915/45371

6. Campos, E. (2016). Cristianismo y revolución. El origen de Montoneros. Edhasa.

7. Caruso, V., Campos, E., Vigo, M. y Acha, O. (2017). Izquierda peronista: una categoría útil para el análisis histórico. Historiografías, 14, 68-90. https://doi.org/10.26754/ojs_historiografias/hrht.2017142337

8. Dawyd, D. (2014). Corrientes y nucleamientos del sindicalismo opositor peronista. Entre la CGT de los Argentinos y el regreso de Perón, 1970-1973. Quinto Sol, 18 (2), 1-21. https://doi.org/10.19137/qs.v18i2.937

9. Gil, G. (1989). La izquierda peronista (1955-1974). Centro Editor de América Latina.

10. Gillespie, R. (2008). Soldados de Perón. Historia crítica sobre los Montoneros. Sudamericana. 
Caruso, V. Entre el Gran Acuerdo Nacional y Trelew: Alcances y significaciones de los conceptos de socialismo nacional y peronismo

11. González Canosa, M. (2017). "Libres o muertos, jamás esclavos". Marxismo, peronismo y lucha armada: las Fuerzas Armadas Revolucionarias en la Argentina de los primeros setenta. Tempo e Argumento, 22 (9), 364-395. https://doi.org/10.5965/2175180309222017364

12. Koselleck, R. (1993). Futuro Pasado. Paidós.

13. James, D. (1976). The Peronist Left 1955-1975. Journal of Latin American Studies, $8(2), 273-296$.

14. James, D. (1990). Resistencia e integración. El peronismo y la clase trabajadora argentina 1946-1976. Sudamericana.

15. Lanusse, L. (2010). Montoneros. El mito de sus 12 fundadores. Zeta.

16. Nahmías, G. (2013). La batalla peronista. De la unidad imposible a la violencia politica (Argentina 1969-1973). Edhasa.

17. Needham, R. (1975). Polythetic Classification: Convergence and Consequences. Man, 10, 349-369.

18. Otero, R. (2019). Montoneros y la memoria del peronismo. Prometeo.

19. Perón, J. D. (2017). La hora de los pueblos/Latinoamérica: Ahora o nunca. Biblioteca del Congreso de la Nación.

20. Pittaluga, R. (2006). La memoria según Trelew. Sociohistórica, 19-20, 81-111. https://www.sociohistorica.fahce.unlp.edu.ar/article/view/SHn19-20a04

21. Pittaluga, R. (2016). La inteligencia obrera. Notas sobre la experiencia política de los trabajadores en los años '70. Cuadernos LIRICO, 15, 1-15. https://doi.org/10.4000/lirico.2845

22. Raimundo, M. (2000). Compañero y los orígenes del Peronismo Revolucionario. Sociohistórica, 8, 203-226. https://www.sociohistorica.fahce.unlp.edu.ar/article/view/SHn08a07

23. Raimundo, M. (2004). Izquierda peronista, clase obrera y violencia armada: una experiencia alternativa. Sociohistórica, 15-16, 99-128. https://www.sociohistorica.fahce.unlp.edu.ar/article/view/SHn15-16a04

24. Slipak, D. (2015). Las revistas montoneras. Cómo la organización construyó su identidad a través de sus publicaciones. Siglo XXI.

25. Williams, R. (1994). Sociología de la cultura. Paidós. 